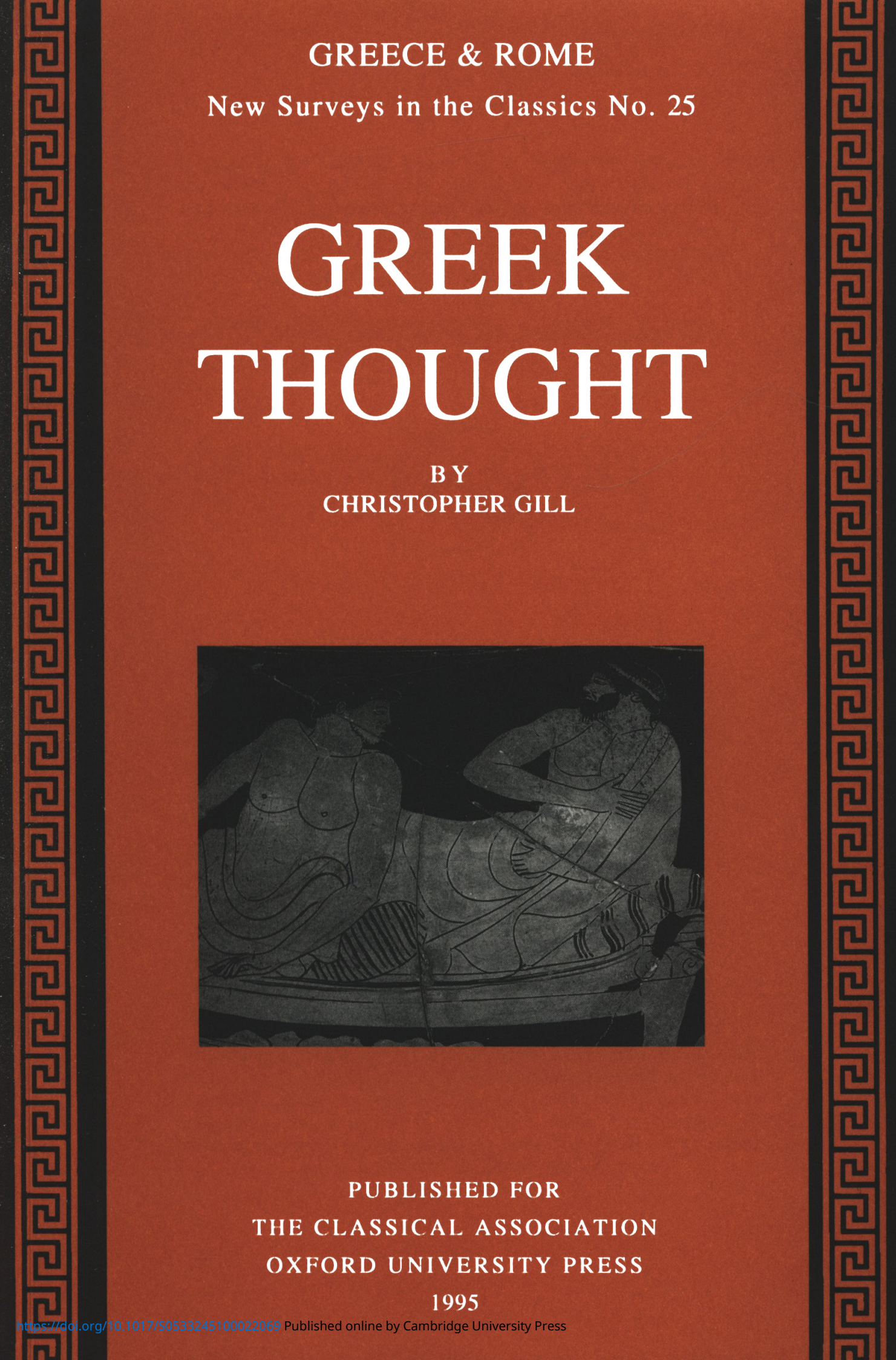


The Classical Association is the largest classical organization in Great Britain. It has a world-wide membership, and unites the interests of all who value the study of the languages, literature and civilizations of Ancient Greece and Rome. For further information contact the Hon. Treasurer, Mr R. Wallace, B.A., M.A., Department of Classics, University of Keele, Keele, Newcastle under Lyme, Staffs ST5 5BG.

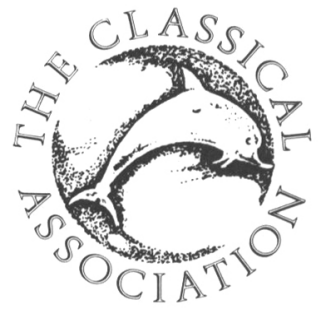

Regular subscribers to Greece $\mathcal{E}$ Rome receive a free copy of each number in this series. Additional copies may be obtained from the Hon. Treasurer of the Classical Association (Mr R. Wallace, Department of Classics, University of Keele, Keele, Newcastle under Lyme, Staffs ST5 5BG). A list of Surveys currently in print may be found at the back of this booklet. 


\section{Greece $\mathcal{E}$ Rome}

NEW SURVEYS IN THE CLASSICS No. 25

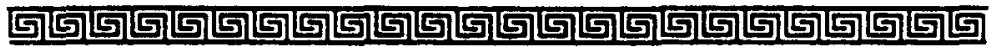

\section{GREEK THOUGHT}

B Y

CHR IS T OPHER GILL

Published for the Classical Association

OXFORD UNIVERSITY PRESS

1995 
Oxford University Press, Walton Street, Oxford ox2 6DP

Oxford New York Toronto

Delhi Bombay Calcutta Madras Karachi

Petaling faya Singapore Hong Kong Tokyo

Nairobi Dares Salaam Cape Town

Melboume Auckland

and associated companies in

Berlin Ibadan

ISSN 0017-3835

ISBN $019,22074-3$

(C) Oxford University Press, 1995

Printed in Great Britain

by Bell and Bain Ltd.,

Glasgow 


\section{CONTENTS}

Note on Conventions $\quad$ v

I Introduction 1

II Models of the Self 5

$\begin{array}{lr}\text { III Ethics and Values } & 20\end{array}$

IV Individuals in Communities $\quad 43$

V The Norms of Nature $\quad 67$

VI Conclusion 90

Bibliographical Note on Greek Philosophy 94

$\begin{array}{ll}\text { About the author } & 98\end{array}$

Index of names, subjects, and passages 99 